\title{
Investigation of the nominal tooth root stress for external, cylindrical gears with symmetric and asymmetric profile
}

\author{
D DEBRECZENI and G BOGNAR \\ Institute of Machine and Product Design \\ University of Miskolc \\ Miskolc-Egyetemvaros H-3515 \\ HUNGARY
}

\begin{abstract}
The determination of tooth bending strength is a basic issue in gear design. This work presents the change of nominal tooth root stress of external toothed, cylindrical gears depending on the geometry used. The nominal tooth root stress is analyzed with using finite element simulations. The numerical calculations are executed in Abaqus. The imported geometries are produced by our own program in MATLAB. The boundary conditions to the models are defined accordance with the most significant analytical methods used in practice. This approach allows mapping direct correlation analysis by these calculations. The optimization of computational capacity used is also considered. In addition to the examination of the significant tooth stress value of symmetrical element pairs, the position of the critical cross-section is also analyzed. The effect of the asymmetric design of the tooth profile on the nominal tooth root stress is also presented in our investigations. The purpose of the numerical simulations carried out here is to determine the effect of the coast side angle on the magnitude of the significant tooth root stress and the position of the critical cross-section.
\end{abstract}

Key-Words: Cylindrical gear, tooth root stress, FEM, ISO 6336, AGMA 2001

Received: October 2, 2019. Revised: March 24, 2020. Accepted: April 10, 2020. Published: April 22, 2020.

\section{Introduction}

The modern demand for power drive elements is the continuous increase in torque transmitted at the same dimensions. This objective makes it increasingly important for development engineers to make accurate estimates of the load capacity of gears. This ensures the required probability of serial production failure. As a result, many studies are focused on mapping and extending the boundaries of standardized European [1] and American [2], [3] procedures, for example Li [4] 's work on the effect of addendum factor and Zhan' $\mathrm{s}$ [5] work on numerical computation of the results of AGMA [2], [3]. In the study by Döbereiner [6] it was shown that the calculation procedure of the European calculation method usually leads to oversizing of the load capacity in case of high and sometimes helical teeth. The significance of the change of load direction is demonstrated in Brinck's dissertation [7]. The effect of centrifugal force on the tooth root capacity of high-speed, narrow-rimmed, webbed gears has been investigated by Li [8]. An example of a mathematical model based on the ISO [1] standard for a more accurate determination of the tooth root stress has been found by Sánchez et al. [9]. The solutions developed by the authors is based on the load distribution model described by Pedrero et al. [10].
Increasing demand on tooth load capacity have resulted the appearance of asymmetric profiles in several areas. The analysis of these pair of gears and their integration into standardized methods have been addressed, among others, by Langheinrich [11] and Cavdar et al. [12] [13]. Numerical examination of the significance of asymmetric profiles is found in the work of Pedersen [14] and PrabhuSekar and Muthuveerappan [15], while the experimental analysis is found in Demet and Ersoyoğlu [16]. Examination of the effect of asymmetric design on the bending strength can also be found in the work of Kapelevich [17] and Senthil Kumar et al. [18], where the authors emphasized the determination of the optimum profile shift coefficient for the tension.

In determining the load capacity, the effect of increasing the tension due to too narrow a rim thickness, which is considered by a separate factor of the ISO standard, can in many cases occur. The importance of the rim thickness chosen has also been addressed in recent studies such as Mallesh et al. [19].

The standardized calculation methods imply a number of theoretical approaches. For example the negligation of certain stress components or the definition of dangerous cross-section. This work analyzes these theoretical approaches according to finite element calculations. First, the most important questions of precise finite element modeling of 
cylindrical gears for tooth root stress calculation are presented. The numerical results of symmetrical element pairs are compared with the results and definitions of European [1] and American [2], [3] standards. After symmetric profiles, the effect of asymmetry in the profile on the value and position of maximum tooth root stress is presented based on numerical calculations.

In this work the correlation of the different methods for the calculation of nominal tooth root stress is presented. The obtained results give base information for the discretion of the significance of a notch in tooth root geometry and draw attention to the potential of use of asymmetrical design.

\section{The setting of FE models}

The numerical calculations performed refer to the plane deformation state in accordance with the most significant analytical methods in practice. Thus, only plane models are used in the investigations. This approach allows mapping the behavior of applied geometry using finite element analysis with minimal computational capacity and direct correlation analysis by analytical methods. The modeling of the gear wheels on the Pfauter machining site is done by Litvin [20] using a proprietary program.

Elemental contact is defined as Hertz's frictionless contact. The contact gears were treated as separate elements throughout the calculation.

In the current simulations, a quadratic quadrilateral mesh has been used with the greatest possible stability of the results. The element size required in the tooth root was determined by preliminary calculations depending on the module used. In the current models, the average distance between adjacent nodes on the examined tooth curve is $0.05 \%$ of the tooth height.

When defining a tooth tension image, by examining a geometrically well-defined area of a given tooth, it seems obvious to greatly reduce the extent of the imported geometry. There are basically two ways to do this, namely by specifying the number of teeth considered and specifying the thickness of the rims.

The definition of the number of teeth per element in the simulation, according to Langheinrich [11], should preferably be set to 5 . In all cases, the tooth under examination is located in the center, which in this case represents 2-2 additional teeth on each side. Langheinrich evaluated the accuracy of the simulation for the calculation of the tooth stress using equation (1). Here $\mathrm{Nz}$ represents the number of teeth considered in the simulation while Nzmax represents the actual number of teeth on the gear.
The loaded tooth is always centered on the two sides by the same number of unloaded adjacent tooth. The sum of these determines the value of $\mathrm{Nz}$.

$$
\Delta \sigma_{N Z}=\frac{\sigma_{N Z}-\sigma_{N z \max }}{\sigma_{N Z \max }}
$$

Langheinrich's results in this regard are illustrated in figure 1. It can be seen that "further increasing the number of teeth taken into consideration by 5 does not result in a significant change in the amount of tooth tension."

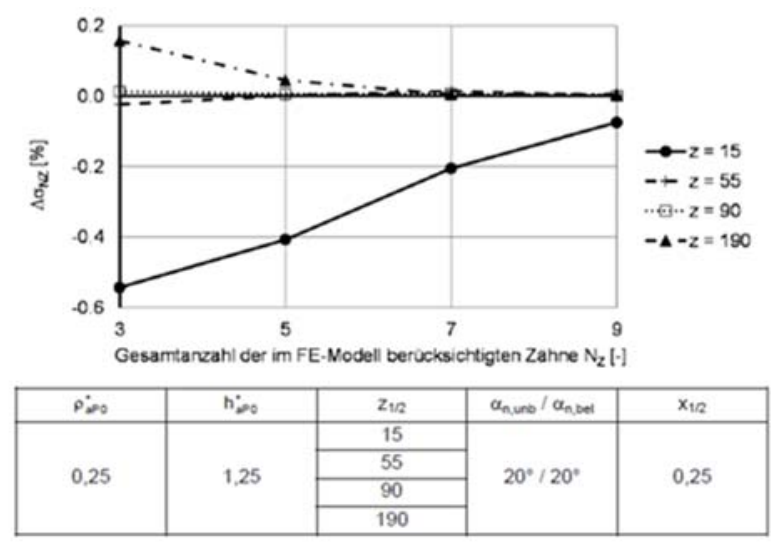

Fig.1 Numerical tooth stress dependence of tooth number. [11]

According to the ISO [1] standard, the rim thickness factor should be chosen to be approximately 3 times the normal module thickness. To completely exclude the effects of the wheel hub being too narrow, the models used have a crown thickness of 4 times the module.

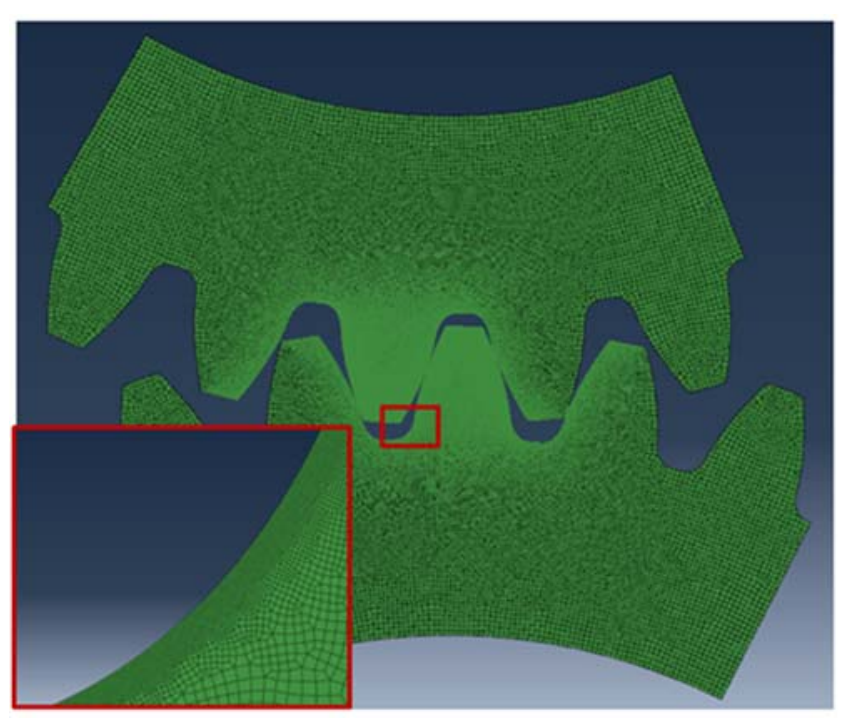

Fig.2 Structure of FE models. 
The models with the geometric constraints shown in figure 2 were also compared to full-scale cases by selecting random sample pairs. Comparisons have confirmed that the effect of the chosen geometric boundaries on results is negligible.

\section{Correlation of the results of symmetric element pairs}

The evolution of the tooth tension of symmetrical teeth is presented by correlating the results of FEM, ISO [1] and AGMA [2], [3]. The gear types used in the relevant investigations are summarized in table 1. Related pairs are always identical. The perimeter line pressure is $300 \mathrm{~N}$. Tooth markings with code number m5z35rf02a2020 can be interpreted as follows:

- normal module: $5 \mathrm{~mm}$

- number of teeth: 35

- profile shift factor: 0

- angle, drive side (side A): $20^{\circ}$

- profile angle, coast side (side B): $20^{\circ}$

- helix angle: $0^{\circ}$

- dedendum factor: 1,25

- root radius factor of the reference profile: 0.2

- rim thickness: $4 *$ normal module

Table 1 Symmetric pairs of elements

\begin{tabular}{|c|c|c|c|c|c|c|c|c|c|c|}
\hline Number & Notation & $\begin{array}{c}\mathrm{m}_{\mathrm{n}} \\
{[\mathrm{mm}]}\end{array}$ & $\begin{array}{c}z_{1} / z_{2} \\
{[-]}\end{array}$ & $\begin{array}{c}x_{1} / x_{2} \\
{[-]}\end{array}$ & $\begin{array}{l}a_{6} \mathrm{~A} \\
{\left[{ }^{\circ}\right]}\end{array}$ & $\begin{array}{l}a_{6} B \\
{\left[{ }^{\circ}\right]}\end{array}$ & $\begin{array}{l}B \\
{\left[{ }^{\circ}\right]}\end{array}$ & $\begin{array}{c}h_{\omega \infty} 0^{\circ} \\
{[-]}\end{array}$ & $\begin{array}{c}P 0_{0}^{\circ} \\
{[-]}\end{array}$ & $\begin{array}{c}S_{R} \\
{\left[\mathrm{X}_{\mathrm{R}}\right]}\end{array}$ \\
\hline 1 & m5z35rf02a1515 & 5 & $35 / 35$ & $0 / 0$ & 15 & 15 & 0 & 1.25 & 0.2 & 4 \\
\hline 2 & $\mathrm{~m} 5 \mathrm{z} 35 \mathrm{rf} 02 \mathrm{a} 2020$ & 5 & $35 / 35$ & $0 / 0$ & 20 & 20 & 0 & 1.25 & 0.2 & 4 \\
\hline 3 & m5z35rf02a 2525 & 5 & $35 / 35$ & $0 / 0$ & 25 & 25 & 0 & 1.25 & 0.2 & 4 \\
\hline 4 & m5z35rf03a1515 & 5 & $35 / 35$ & $0 / 0$ & 15 & 15 & 0 & 1.25 & 0.3 & 4 \\
\hline 5 & $\mathrm{mSz} 35 \mathrm{rf0} 3 \mathrm{a} 2020$ & 5 & $35 / 35$ & $0 / 0$ & 20 & 20 & 0 & 1.25 & 0.3 & 4 \\
\hline 6 & m5z35rf03a2525 & 5 & $35 / 35$ & $0 / 0$ & 25 & 25 & 0 & 1.25 & 0.3 & 4 \\
\hline 7 & m5z35rf04a1515 & 5 & $35 / 35$ & $0 / 0$ & 15 & 15 & 0 & 1.25 & 0.4 & 4 \\
\hline 8 & m5z35rf04a2020 & 5 & $35 / 35$ & $0 / 0$ & 20 & 20 & 0 & 1.25 & 0.4 & 4 \\
\hline 9 & m5z105rf02a1515 & 5 & $105 / 105$ & $0 / 0$ & 15 & 15 & 0 & 1.25 & 0.2 & 4 \\
\hline 10 & m5z105rf02a2020 & 5 & $105 / 105$ & $0 / 0$ & 20 & 20 & 0 & 1.25 & 0.2 & 4 \\
\hline 11 & m5z105rfo2a2525 & 5 & $105 / 105$ & $0 / 0$ & 25 & 25 & 0 & 1.25 & 0.2 & 4 \\
\hline 12 & m5z105rf03als15 & 5 & $105 / 105$ & $0 / 0$ & 15 & 15 & 0 & 1.25 & 0.3 & 4 \\
\hline 13 & $\mathrm{~m} 5 \mathrm{z} 105 \mathrm{rf0} 3 \mathrm{a} 2020$ & 5 & $105 / 105$ & $0 / 0$ & 20 & 20 & 0 & 1.25 & 0.3 & 4 \\
\hline 14 & m5z105rf03a2525 & 5 & $105 / 105$ & $0 / 0$ & 25 & 25 & 0 & 1.25 & 0.3 & 4 \\
\hline 15 & m5z105rf04a1515 & 5 & $105 / 105$ & $0 / 0$ & 15 & 15 & 0 & 1.25 & 0.4 & 4 \\
\hline 16 & m5z105rf04a2020 & 5 & $105 / 105$ & $0 / 0$ & 20 & 20 & 0 & 1.25 & 0.4 & 4 \\
\hline
\end{tabular}

It is important to emphasize that even the European standard only considers bending stress, whereas the AGMA standard considers the compressive stress of the tooth root in the calculation. Based on these, it is expected that the AGMA standard will typically have lower tension values, since the consideration of the compressive load considered to be the relevant drawn pull is beneficial. However, we should not forget that there are several differences in the theoretical approach of the two methods. These differences can sometimes disrupt the tendency. However, the theoretical importance of taking stress into account is clearly enhanced by increasing the profile angle. As a result, a significant profile angle dependence can be predicted for the AGMA standard nominal stress calculation compared to the ISO calculation, which is reflected in the results of figure 3 .

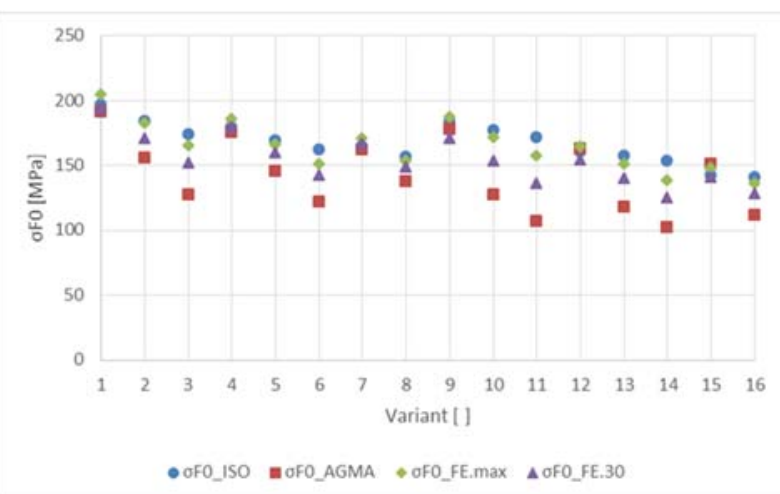

Fig.3 Tooth root stress for symmetric element.

However, the finite element models show a difference in the position of the dangerous cross section compared to the standardized solutions. Therefore, it is worth examining the evolution of numerical stress values in the ISO standard cross section. These results are also shown in figure 3 . However, the discrepancies shown here in relation to the European direction no longer show a clearly more favorable correlation. Figure 4.illustrates the differences of the tooth root stress values.

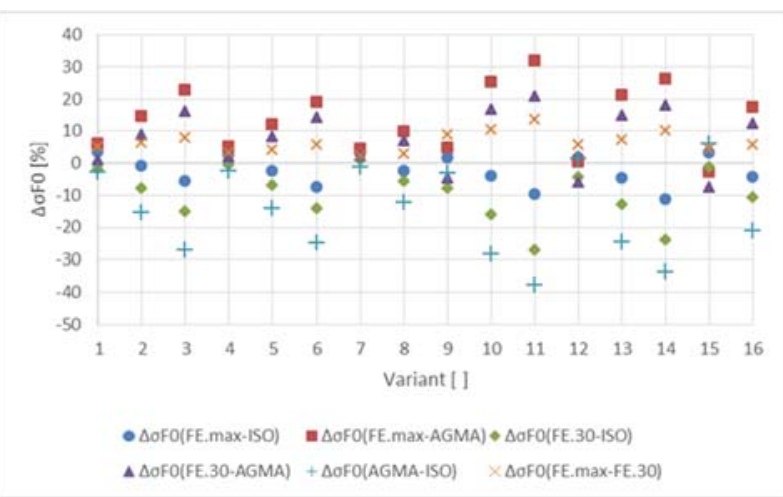

Fig.4 Differences of tooth root stress values for symmetric element.

It is important that different standardized methods use different permissible tensions to determine load capacity. As a result, the nominal stresses under the various procedures do not necessarily reflect the ratio of safety factors. A detailed description of the permissible tooth root stress is not the subject of current work. But a brief touch on the question is important to illustrate the subtlety of the topic. Table 2 summarizes the parameters taken into account in determining the stresses according to different methods.

Figure 5 summarizes the evolution of the safety factors obtained for the tested variants based on ISO 
and AGMA. It can be seen that the AGMA standard typically predicts significantly lower safety factors despite the lower tooth root stress values.

Table 2 Parameters considered for the determination of safety factors

\begin{tabular}{|c|c|c|}
\hline Material & \multicolumn{2}{|c|}{$16 \mathrm{MnCr} 15$} \\
\hline Heat treatment & \multicolumn{2}{|c|}{ Case hardened } \\
\hline Other treatment & \multicolumn{2}{|c|}{ No } \\
\hline Young's modulus & \multicolumn{2}{|c|}{$206000 \mathrm{MPa}$} \\
\hline Poisson's ratio & \multicolumn{2}{|c|}{0.3} \\
\hline Quality of material & \multicolumn{2}{|c|}{ MQ } \\
\hline Number of stress cycles & \multicolumn{2}{|c|}{$3 \cdot 10^{6}$} \\
\hline \multicolumn{3}{|c|}{ AGMA 2001 / AGMA 2101} \\
\hline Temperature factor & $\mathrm{K}_{\mathrm{T}} / \mathrm{Y}_{\theta}$ & 1 \\
\hline Reliability factor & $\mathrm{K}_{\mathrm{R}} / \mathrm{Y}_{2}$ & 1 \\
\hline \multicolumn{3}{|c|}{ ISO 6336} \\
\hline Stress correction factor & $\mathrm{Y}_{\mathrm{ST}}$ & 2 \\
\hline Relative notch sensitivity factor & $\mathrm{Y}_{\text {BeelT }}$ & 0.997 \\
\hline Relative surface factor & $\mathrm{Y}_{\text {ReitT }}$ & 0.964 \\
\hline Size factor & $\mathrm{YX}$ & 1 \\
\hline
\end{tabular}

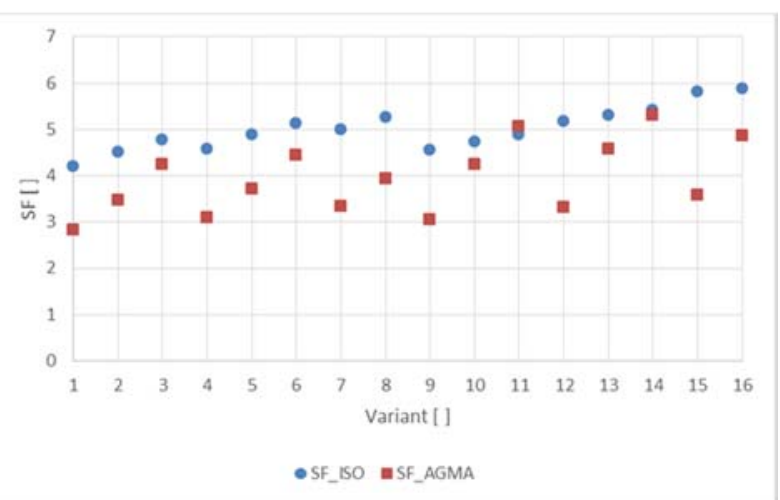

Fig.5 Differences of tooth root stress values for symmetric element.

When describing the position of a critical point, it is worth choosing the ISO standard as a benchmark. The European calculation uses a fixed dangerous cross-section. The American method, on the other hand, makes the dangerous cross-section dependent on the contact position. Numerical calculations also show a point-to-point shift at the critical point position. Of course, it is still worth assigning the dangerous cross-section to the critical point at the outer position of the single-tooth pair contact phase (point B).

The angular values $\delta$ of the tangents of the dangerous cross-sections to the centerline in the position of tooth top (point $\mathrm{A}$ ) and in the point $\mathrm{B}$ connections are shown in figure 6 . According to the US standard, the tangent in point $\mathrm{B}$ is between $26.6^{\circ}$ and $33.2^{\circ}$, and in point $\mathrm{A}$ is $13.7^{\circ}$ and $17.9^{\circ}$. The oscillation of the position of the numerical stress is much more significant, which in the case of the tested variants can be in the range of $38.0-50.1^{\circ}$ in point $\mathrm{B}$ and in the range of $27.3^{\circ}-45.2^{\circ}$ in point $\mathrm{A}$.

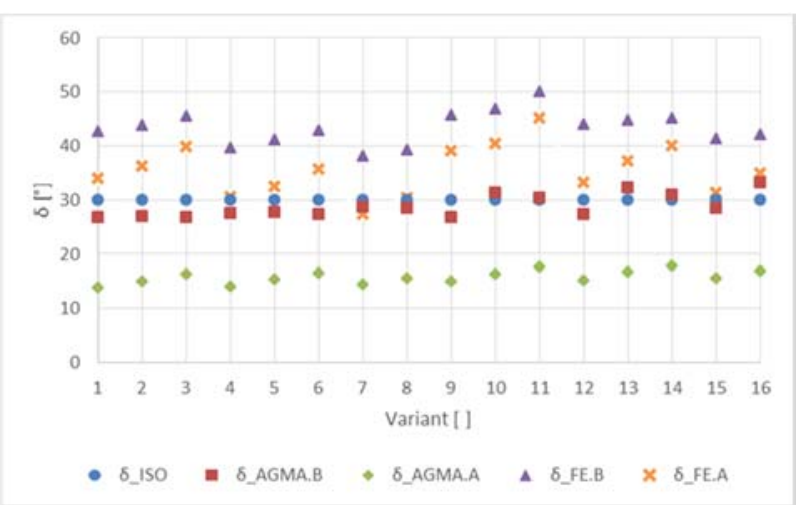

Fig.6 Dangerous cross-section of symmetric pairs.

Based on the investigations, the migration of the tangent of the dangerous cross-section between the coupling points $\mathrm{A}$ and $\mathrm{B}$ can also be determined. The results are summarized in Figure 7 . The American standard shows $10.5^{\circ}-16.4^{\circ}$ for the variants tested, while the finite element models show an average migration of $4.8^{\circ}-11.0^{\circ}$.

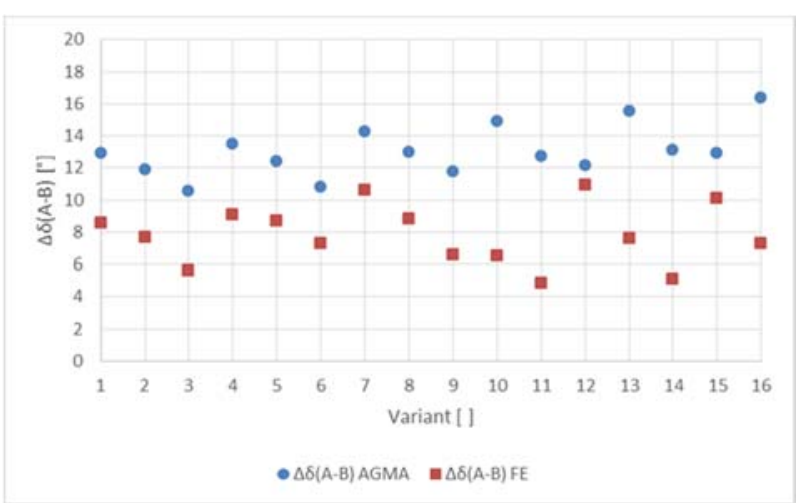

Fig. 7 Move of dangerous cross-section of symmetric pairs.

Element pairs examined so far all had the same dedendum factor as shown in Table 1. Models of elevated dedendum have also been analysed in order to confirm the studies conducted so far. The gears used here are summarized in Table 3.

Table 3 Symmetric pairs of elements with increased dedendum factor

\begin{tabular}{|c|c|c|c|c|c|c|c|c|c|c|}
\hline Number & Notation & $\begin{array}{c}\mathrm{m}_{\mathrm{s}} \\
{[\mathrm{mm}]}\end{array}$ & $\begin{array}{c}z_{1} / z_{2} \\
{[\cdot]}\end{array}$ & $\begin{array}{c}x_{1} / x_{2} \\
{[-]}\end{array}$ & $\begin{array}{l}a_{6} \mathrm{~A} \\
{\left[{ }^{\circ}\right]}\end{array}$ & $\begin{array}{l}a_{e} B \\
{\left[{ }^{\circ}\right]}\end{array}$ & $\begin{array}{l}B \\
{\left[{ }^{\circ}\right]}\end{array}$ & $\begin{array}{c}\mathrm{h}_{\Delta 0_{0} 0^{\circ}} \\
{[-]}\end{array}$ & $\begin{array}{c}P_{\Delta} 0^{\circ} \\
{[-]}\end{array}$ & $\begin{array}{c}\mathrm{S}_{\mathrm{g}} \\
{\left[\mathrm{X}_{\mathrm{m}}\right]}\end{array}$ \\
\hline 17 & m5z35rf02hfl 35 al616 & 5 & $35 / 35$ & $0 / 0$ & 16 & 16 & 0 & 1.35 & 0.2 & 4 \\
\hline 18 & m5z35rfozhfl $35 \mathrm{a} 2020$ & 5 & $35 / 35$ & $0 / 0$ & 20 & 20 & 0 & 1.35 & 0.2 & 4 \\
\hline 19 & m5z35rfozhfl $35 \mathrm{a} 2525$ & 5 & $35 / 35$ & $0 / 0$ & 25 & 25 & 0 & 1.35 & 0.2 & 4 \\
\hline
\end{tabular}

The results of the pairs of elements in Table 3 are illustrated in Figure 8. It can be seen that both the percentage difference in the maximum numerical main stress by the ISO standard and the position of the dangerous cross-section justify the trends in Figures 4 and 6. 


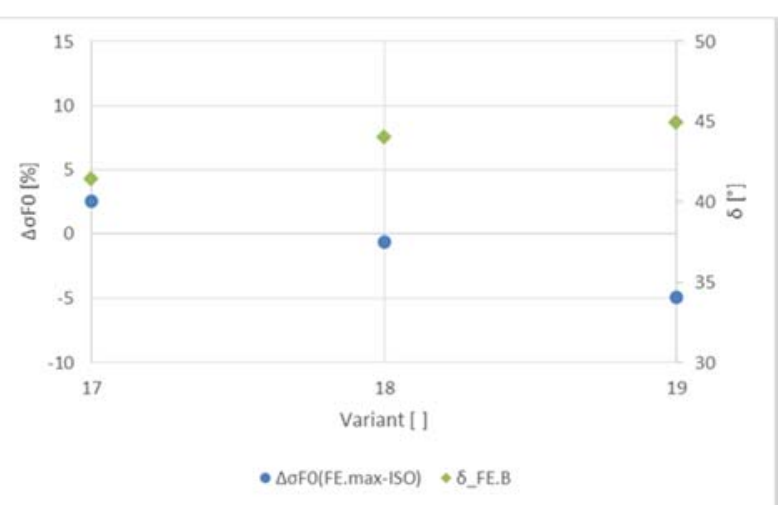

Fig.8 Results of symmetric pairs with increased dedendum factor.

\section{Effect of asymmetry}

In this section, the influence of different drive and coast side profile angle on numerical results is presented. The tests are also evaluated based on the magnitude and position of the first main stress in the cage. Asymmetric variants used in the calculations are denoted in accordance with the symmetric variants summarized in table 1.

When evaluating the effect of the coast side profile angle, it is worth expressing the profile angle of the coast side as a function of the drive side. As a result, profiles are obtained which can be used to present the effect of the changes in each characteristic in a clear format. Accordingly, figure 9 summarizes the dependence of the tooth root stress on the coast side profile angle of the models with 0.2 and 0.3 root radius factor. The abscissa of the charts shows the increment of the cost side profile angle relative to the drive side. Thus, the position 0 denotes the symmetric element pair. It can be seen that increasing the tooth root radius of the reference profile slightly mitigates the effect of the change of the coast profile angle on the active side. However, this does not result in a difference of more than $0.1 \% /{ }^{\circ}$ in current experiments.

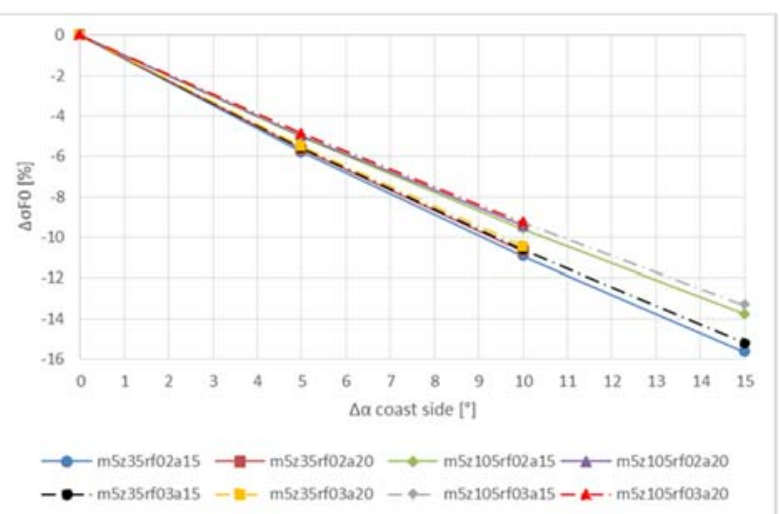

Fig.9 Tensile stress of asymmetric battery pairs.
In the cases studied so far, each variant had a dedendum factor of 1.25. This parameter of the tooth profile is decisive for the influence of the examined asymmetry on the dominant tooth tension. Accordingly, figure 10 shows the results of two sets of gears which differ only in their dedendum factor. For teeth with different dedendum factors, there is an interesting trend between the effect of the coast side profile angle and the applied dedendum factor. The differences between the two tendency curves, which differ only in their height, can be eliminated by a very good approximation, taking into account the proportion of the dedendum factors. As a result, by compensating the series of Fig. 10 by applying series (2), the asymmetry sensitivity of the pairs of different dedendum factors can be covered with a very good approximation as shown in Fig. 11. In this way, the effect of changing the height of the feet, while leaving the other parameters unchanged, can be easily predicted. The displacement of the coupling point $\mathrm{B}$ as the axis spacing changes can also be treated similarly.

$$
\Delta \sigma F 0[\%]_{h f Y}=\Delta \sigma F 0[\%]_{h f X} \frac{h f Y}{h f X}
$$

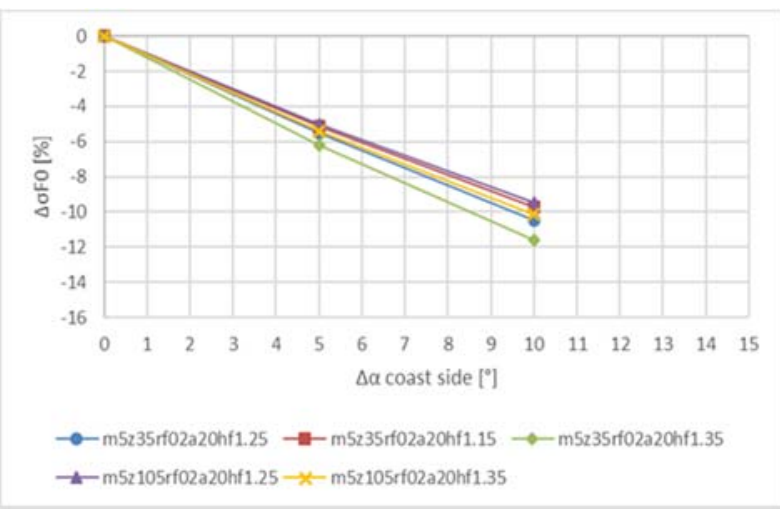

Fig.10 Tension on asymmetric battery pairs with different foot heights.

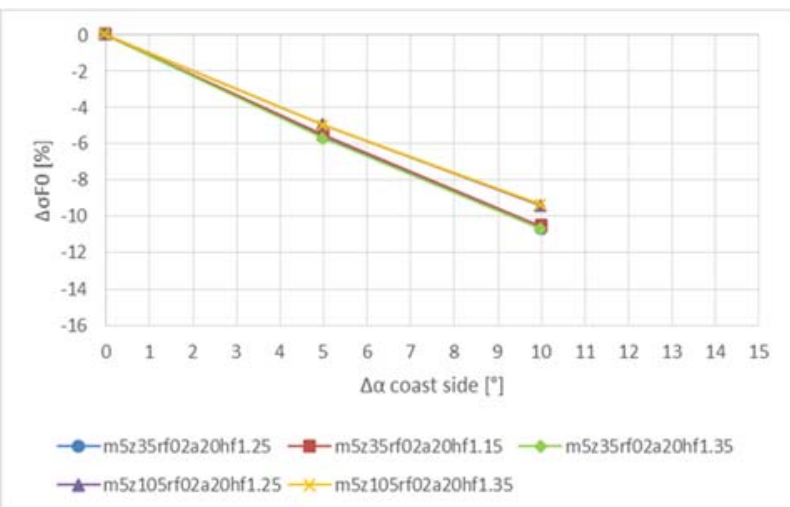

Fig.11 Modified ension on asymmetric battery pairs with different foot heights. 
The effect of the asymmetrical construction of the tooth profile on the position of the dangerous cross-section is shown in figure 12. The position of the critical point is evaluated as a function of the angular change of the $\Delta \delta$ tangents to the centerline of the profiles. Studies show that the increase of the coast profile angle results in a slight migration of the drive sided critical point towards the foot, but this change is negligible for practice.

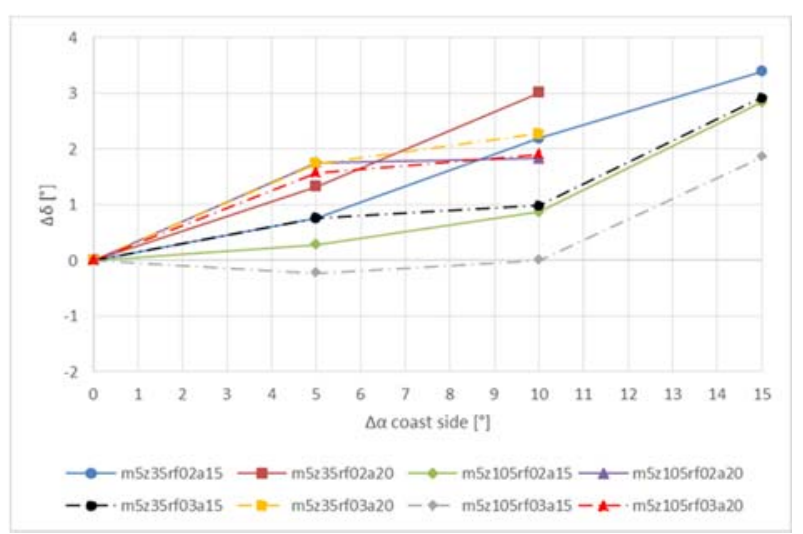

Fig.12 Dangerous cross-section of asymmetric element pairs.

\section{Conclusion}

The tests carried out have shown that for the symmetrical variants tested, the numerically significant maximum tooth stress value correlates well with the ISO standard value. In contrast, the location of the critical cross-section differs from the standardized procedure. The numerical calculations show the shift of the critical point towards the gear body.

Examination of the effect of asymmetry has highlighted the importance of the coast side profile angle of the tooth profile on the drive side first prime stress, which increases with the increase of the dedendum factor. The simulations performed proved that the determination of the dangerous cross-section of the asymmetric profiles can be considered independent of the coast side angle. Consequently, the position of the drive sided dangerous point of the asymmetric variants can be the same as the symmetric element pair corresponding to the active side profile angle.

\section{References:}

[1] ISO 6336-3,Calculation of load capacity of spur and helical gears - Part 3: Calculation of tooth bending strength,International Organization for Standardization (Geneva), 2007.
[2] AGMA 2001-D04,Fundamental Rating Factors and Calculation Methods for Involute Spur and Helical Gear Teeth,American Gear Manufacturers Association (Alexandria), 2004.

[3] AGMA 908,Geometry Factors for Determining the Pitting Resistance and Bending Strength of Spur, Helical and Herringbone Gear Teeth, American Gear Manufacturers Association (Alexandria), 1989.

[4] Li S, Effect of addendum on contact strength, bending strength and basic performance parameters of a pair of spur gears,Mech. Mach. Theory, Vol.43, No.12,2008, pp. 1557-1584. doi.org/10.1016/j.mechmachtheory.2007.12.01 0.

[5] Zhan J, Fard M and Jazar R, A quasi-static FEM for estimating gear load capacity,Measurement,Vol.75, 2015, pp. 4049.doi.org/10.1016/j.measurement.2015.07.036

[6] Döbereiner R,Tragfähigkeit von HochverzahnungengeringerSchwingungsanregung, Diss., Technical University of Munich (Munich), 1998.

[7] Brinck P,ZahnfusstragfähigkeitoberflächengehärteterStirnräderbeiLastrichtungsumkehr, Diss., Technical University of Munich (Munich), 1989.

[8] $\mathrm{Li} \mathrm{S}$, Effects of centrifugal load on tooth contact stresses and bending stresses of thinrimmed spur gears with inclined webs Mech. Mach. Theory,Vol.59, No.1, 2013, pp. 3447.doi.org/10.1016/j.mechmachtheory.2012.08. 011.

[9] Sánchez M B, Pedrero J I and Pleguezuelos M, Critical stress and load conditions for bending calculations of involute spur and helical gears,International Journal of Fatigue, Vol.48, 2013,

38.doi.org/10.1016/j.ijfatigue.2012.11.015.

[10] Pedrero J I, Pleguezuelos M and Muñoz M, Critical stress and load conditions for pitting calculations of spur and helical gear teeth,Mech. Mach. Theory,Vol.46, No.4,2011, pp. 425437.doi.org/10.1016/j.mechmachtheory.2010.1 2.001 .

[11] Langheinrich A 2014 Geometrie, Beanspruchung und VerformungasymmetrischerStirnradverzahnung en,Diss., Technical University of Munich (Munich), 2014.

[12] Cavdar K, Karpat F and Babalik F C, Computer aided analysis of bending strength of involute spur gears with asymmetric profile,J. Mech. 
Des.,Vol.127, No.3, 2005, pp. 477484.doi.org/10.1115/1.1866158.

[13] Karpat F, Cavdar K and Babalik F C, Computer aided analysis of involute spur gears with asymmetric teeth,VDI Berichte,No.1904, 2005, pp. 145-163.

[14] Pedersen N L, Improving bending stress in spur gears using asymmetric gears and shape optimization,Mech. Mach. Theory,Vol.45, No.11, 2010, pp. 17071720,doi.org/10.1016/j.mechmachtheory.2010. 06.004 .

[15] PrabhuSekar R and Muthuveerappan G, Load sharing based maximum fillet stress analysis of asymmetric helical gears designed through direct design - A parametric study,Mech. Mach. Theory,Vol.80, No.10, 2014, pp. 84-102 dx.doi.org/10.1016/j.mechmachtheory.2014.04. 021.

[16] Demet S M and Ersoyoğlu A S, Fatigue Fracture Behaviour of Asymmetric Spur Gear Tooth Under Cyclic Loading,Procedia Structural Integrity,Vol.13, 2018, pp. 20302035.doi.org/10.1016/j.prostr.2018.12.213.
[17] Kapelevich A L, Geometry and design of involute spur gears with asymmetric teeth,Mech. Mach. Theory,Vol.35, No.1, 2000, pp. 117-130. doi.org/10.1016/S0094-114X(99)00002-6.

[18] Senthil Kumar V, Muni D V and Muthuveerappan G, 2008 Optimization of asymmetric spur gear drives to improve the bending load capacity,Mech. Mach. Theory,Vol.43, No.7, 2008, pp. 829858.doi:10.1016/j.mechmachtheory.2007.06.00 6.

[19] Mallesh G, Math V B, Ravitej, Krishna Prasad Bhat $\mathrm{P}$ and Paramesh Kumar M K,Effect of rim thickness on symmetric and asymmetric spur gear tooth bending stress, 14th National Conf. on Machines and Mechanisms (Durgapur), 2009.

[20] Litvin F L,Theory of Gearing United States Government Printing (Washington), 1989. 